Case Report

\title{
Coexistence of GH-Producing Pituitary Macroadenoma and Meningioma in a Patient with Multiple Endocrine Neoplasia Type 1 with Hyperglycemia and Ketosis as First Clinical Sign
}

\author{
A. Herrero-Ruiz, ${ }^{1,2}$ H. S. Villanueva-Alvarado, ${ }^{1}$ J. J. Corrales-Hernández, ${ }^{1,2,3}$ \\ C. Higueruela-Mínguez, ${ }^{1}$ J. Feito-Pérez, ${ }^{4}$ and J. M. Recio-Cordova ${ }^{1,2}$ \\ ${ }^{1}$ Service of Endocrinology and Nutrition, University Clinical Hospital of Salamanca, Paseo de San Vicente No. 58, \\ 37007 Salamanca, Spain \\ ${ }^{2}$ Department of Medicine, University of Salamanca, Campus Miguel de Unamuno, s/n, 37007 Salamanca, Spain \\ ${ }^{3}$ Cancer Research Institute (IBMCC-CSIC/USAL) and Institute for Biomedical Research, University of Salamanca, Salamanca, Spain \\ ${ }^{4}$ Service of Anatomic Pathology, University Clinical Hospital of Salamanca, Paseo de San Vicente No. 58, 37007 Salamanca, Spain
}

Correspondence should be addressed to A. Herrero-Ruiz; aherreror@saludcastillayleon.es

Received 29 June 2017; Accepted 10 October 2017; Published 1 November 2017

Academic Editor: Lucy Mastrandrea

Copyright (C) 2017 A. Herrero-Ruiz et al. This is an open access article distributed under the Creative Commons Attribution License, which permits unrestricted use, distribution, and reproduction in any medium, provided the original work is properly cited.

\begin{abstract}
We present the clinical case of a patient who was admitted with an onset of diabetes mellitus (DM) with associated ketosis and whose clinical, hormonal, and radiological evolution revealed the presence of primary hyperparathyroidism, pancreatic neuroendocrine tumor, and GH-producing pituitary macroadenoma in the context of multiple endocrine neoplasia type 1 (MEN1). DM is relatively common in cases of acromegaly, but it is not generally associated with ketosis. Simultaneously, the patient presented a meningioma, which is associated with pituitary macroadenoma only in extremely rare cases.
\end{abstract}

\section{Introduction}

Multiple endocrine neoplasia type 1 (MEN1) is an autosomal dominant syndrome characterized by the combined appearance of tumors in the parathyroid glands, pancreas islet cells, and the anterior pituitary. This type of syndromes is known to be associated with the secretion of a wide range of hormones which are often responsible for alterations in the glucose metabolism. However, the presence of diabetic ketosis and/or ketoacidosis is a rare clinical situation, with very few cases reported so far. Also, and in an even less common case, the patient simultaneously presented a GH-producing pituitary macroadenoma and a meningioma, a combination which is extremely rare.

\section{Case Report}

We present the clinical case of a 35-year-old woman with a history of Chagas disease who was admitted in the Unit of
Endocrinology with hyperglycemia and ketosis in the context of onset of DM with weakness, polydipsia, and polyuria of 4 months of evolution, together with a weight loss of $10 \mathrm{~kg}$ over the last 6 months. Also, she presented amenorrhea for 4 months and hyperhidrosis. The examination revealed a slight prognathism, growth of acral parts of the body, and grade 1 goiter with a 2 -cm left thyroid nodule.

The analysis showed glucose $248 \mathrm{mg} / \mathrm{dL}$, HbAlc $14.6 \%$, calcium $11.3 \mathrm{mg} / \mathrm{dL}$, phosphorus $2.3 \mathrm{mg} / \mathrm{dL}$, and urine calcium $513 \mathrm{mg} / 24 \mathrm{~h}$. Given the initial findings, the study was expanded to include a hormone profile test (Table 1), a thyroid ultrasound $(28 \times 16-\mathrm{mm}$ mixed nodule in the left lobe and $1.2 \times 0.9 \mathrm{~cm}$ hypoechoic nodule in the right infrathyroid region, which suggests an enlarged parathyroid gland), and an ultrasound-guided fine-needle aspiration (UGFNA) of the left thyroid nodule compatible with benign follicular nodule.

The endocrine study confirmed the clinical suspicion of primary hyperparathyroidism and GH hypersecretion. The parathyroid SPECT/CT was compatible with right 
TABLE 1: Hormone measurements in plasma.

\begin{tabular}{lcc}
\hline Hormone & Value & Normal range \\
\hline TSH $(\mu \mathrm{UI} / \mathrm{mL})$ & 4.7 & $0.27-4.2$ \\
Free T4 $(\mathrm{ng} / \mathrm{dL})$ & 1.1 & $0.82-1.78$ \\
FSH $(\mathrm{mUI} / \mathrm{mL})$ & 3.3 & $3.5-12.5$ \\
LH $(\mathrm{mUI} / \mathrm{mL})$ & 1.9 & $2.4-12.6$ \\
Estradiol $(\mathrm{pg} / \mathrm{mL})$ & $<5$ & $12.5-166$ \\
Prolactin $(\mathrm{ng} / \mathrm{mL})$ & 59.2 & $4.79-23.3$ \\
GH $(\mathrm{ng} / \mathrm{mL})$ & 48.1 & $0-8$ \\
IGF1 $(\mathrm{ng} / \mathrm{mL})$ & 702 & $109-284$ \\
Cortisol $(\mu \mathrm{g} / \mathrm{dL})$ & 10.5 & $2.69-18$ \\
PTH $(\mathrm{pg} / \mathrm{mL})$ & 203.4 & $11-67$ \\
\hline
\end{tabular}

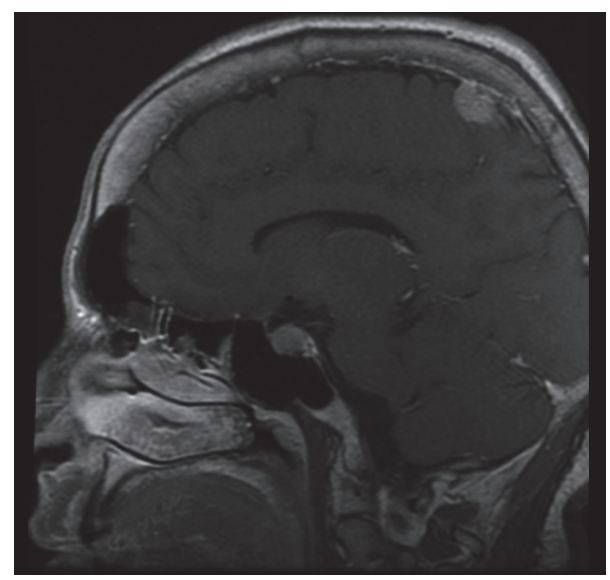

FIGURE 1: (NMR) pituitary macroadenoma and left superior parietal extra-axial lesion compatible with meningioma.

parathyroid adenoma. A nuclear magnetic resonance (NMR) revealed a pituitary macroadenoma of $20 \times 13 \times 15 \mathrm{~mm}$ which spread to the right cavernous sinus, with displacement of the optic chiasm, and a left superior extra-axial parietal lesion of $20 \times 20 \times 12 \mathrm{~mm}$ which suggested a meningioma (Figure 1).

Given these findings and the clinical suspicion of MEN1, the study was completed with a CT scan of the neck, chest, abdomen, and pelvis, which showed a hypervascular heterogeneous mass with lobulated and well-defined edges of $6.8 \times 7.7 \times 6.4 \mathrm{~cm}$ in the tail of pancreas, plus another mass of similar characteristics of $6 \times 4.2 \mathrm{~cm}$ in the uncinate process and at least three more pancreatic focal lesions of less than $1 \mathrm{~cm}$ on the head and neck of pancreas (Figure 2). In the liver there were several hypervascular lesions in segments II and III, of $0.9 \mathrm{~cm}$, compatible with metastatic involvement. Tumor markers revealed increased levels of somatostatin $(30.9 \mathrm{pmol} / \mathrm{L})$, pancreatic polypeptide $(>200 \mathrm{pmol} / \mathrm{L})$, and calcitonin $(9.6 \mathrm{pg} / \mathrm{mL})$, with normal levels of chromogranin A, gastrin, glucagon, and vasoactive intestinal polypeptide.

A somatostatin receptor scintigraphy (OctreoScan) was performed showing a pathological deposit in the tail of

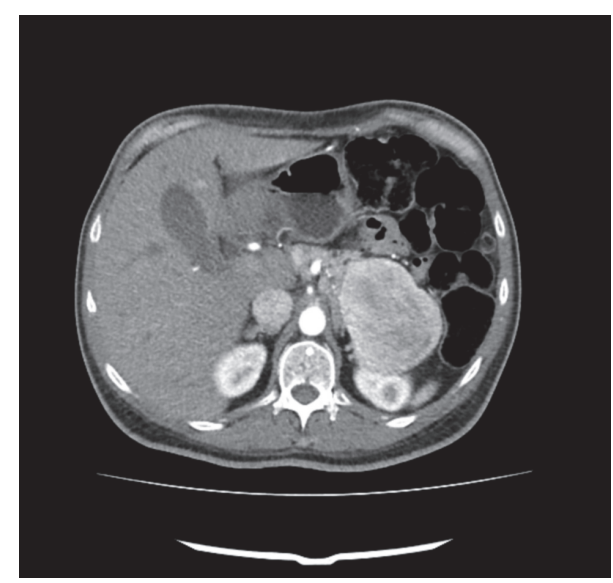

FIGURE 2: (CT) tail of pancreas with hypervascular heterogeneous and well-defined mass with lobulated edges measuring $6.8 \times 7.7 \times$ $6.4 \mathrm{~cm}$.

pancreas which suggested a tumor with expression of somatostatin receptors and also at the upper left parietal level, which was caused by a meningioma (Figure 3). The endoscopic ultrasound-guided fine-needle aspiration biopsy of the mass in the pancreas was compatible with a neuroendocrine tumor (NET). A genetic study confirmed the clinical suspicion of MEN1. The patient was a heterozygous carrier of the pathogenic change c. $1378 \mathrm{C}>\mathrm{T}(\mathrm{p}$. Arg460 $)$.

The patient started treatment with high doses of basalbolus insulin therapy, somatostatin analogs, and cinacalcet. Afterwards, cabergoline was added due to the persistence of high levels of IGF1. The pituitary macroadenoma was resected through a transnasal transsphenoidal and the IGF1 levels went back to normal, with octreotide treatment. The anatomic pathology revealed a pituitary somatotroph adenoma (densely granulated) and the immunohistochemical study: CAM 5.2 (+++), GH (+++), p53 (-), and MIB- $1<1 \%$. An abdominal NMR was performed to control the evolution of her condition, and it still showed two heterogeneous lesions on the head and tail of pancreas, of $5.5 \times 4.5 \times$ $4 \mathrm{~cm}$ and $6 \times 7.5 \times 8 \mathrm{~cm}$, respectively, contrast-enhanced and with well-defined edges. Also, the liver had normal size, morphology, and intensity, and the image did not reveal the lesions described in the CT scan image.

After an assessment by an interdisciplinary board, the patient underwent total pancreaticoduodenectomy, cholecystectomy, and splenectomy. The anatomical pathology showed 7 well-differentiated (G1) NETs in the pancreas, 1 welldifferentiated NET (G1) in the pylorus of $<0.5 \mathrm{~cm}, 14$ lymph nodes in the tail of pancreas with no sign of malignancy, and 2 lymph nodes with NET metastasis out of 12 isolated nodes on the head of pancreas (pT2N1). All the tumors expressed chromogranin A and synaptophysin, with proliferation mediated by Ki67 $<1 \%$, except for the node found in the neck of pancreas, in which it reached 2-3\%. Also, 2 out of the 7 tumors were intensely positive for glucagon (100\%) (Figure 4), and an additional node in the body of pancreas was positive for calcitonin $(70 \%)$, with positive isolated cells for glucagon and somatostatin $(<2 \%)$. 

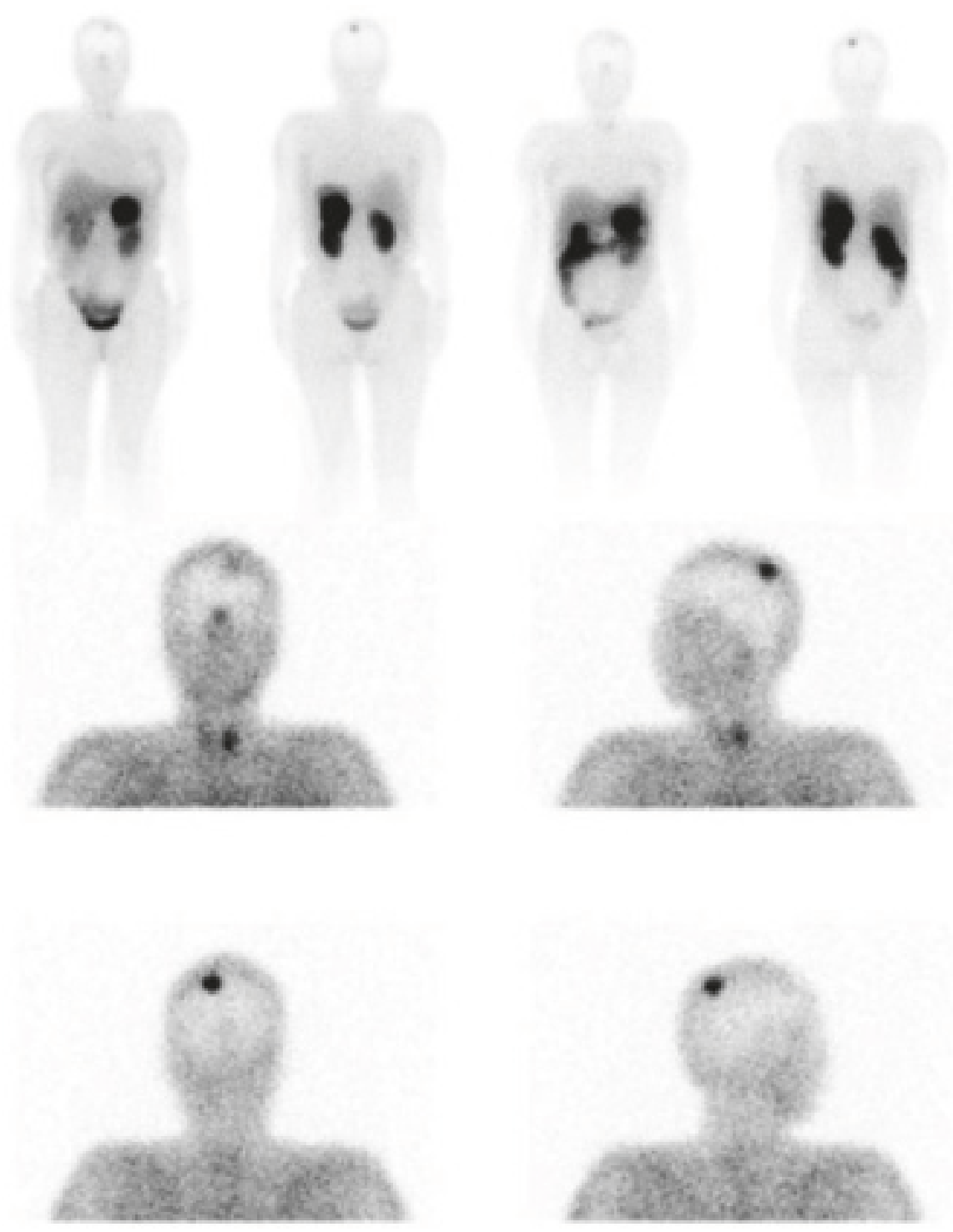

FIgURE 3: OctreoScan showing a pathological deposit at the upper left parietal level caused by meningioma and in the tail of pancreas.

\section{Discussion}

We present the case of a patient with MEN1 with some peculiar features.

(1) DM with ketosis as its first manifestation: alterations in the metabolism of glucose are a common characteristic in acromegaly, with a described prevalence of DM ranging from 19 to $56 \%$ [1-3]. However, these alterations are generally due to the insulin resistance caused by an excess of GH and IGF1, with an increase of gluconeogenesis and a decrease of peripheral glucose uptake $[4,5]$, and it typically does not show a tendency to ketosis, with only 11 cases of ketoacidosis having been described as the first sign of acromegaly [4]. Some authors have analyzed the factors which may predispose to alterations in the glucose metabolism of these patients, and they are related to the levels of IGF1 [1], GH [6], age, body mass index, arterial hypertension, and time of evolution of the disease $[2,3,6]$. In our case, hyperprolactinemia, due to the compression of the pituitary stalk, may have also contributed to the alteration in glucose metabolism through an increase in insulin resistance. Some of the mechanisms suggested to explain this include a decrease in insulin receptors and/or deficiencies at a postreceptor level [4]. McCallum et al. identified an increased prevalence of diabetes and glucose intolerance in patients with MEN1, and several theories have been put forward in which adiponectin and enteropancreatic markers might be involved, or the MEN1 gene, which may cause a predisposition to this resistance [7]. On the other hand, primary hyperparathyroidism has also been associated with an increase in insulin resistance and DM [7]. Therefore, there are several underlying mechanisms which may have contributed to the atypical clinical presentation of our patient.

(2) Another peculiar trait in our case is the concomitant presence of a pituitary tumor and meningioma, because this is a rare clinical situation, with only 33 cases described $[8,9]$. 


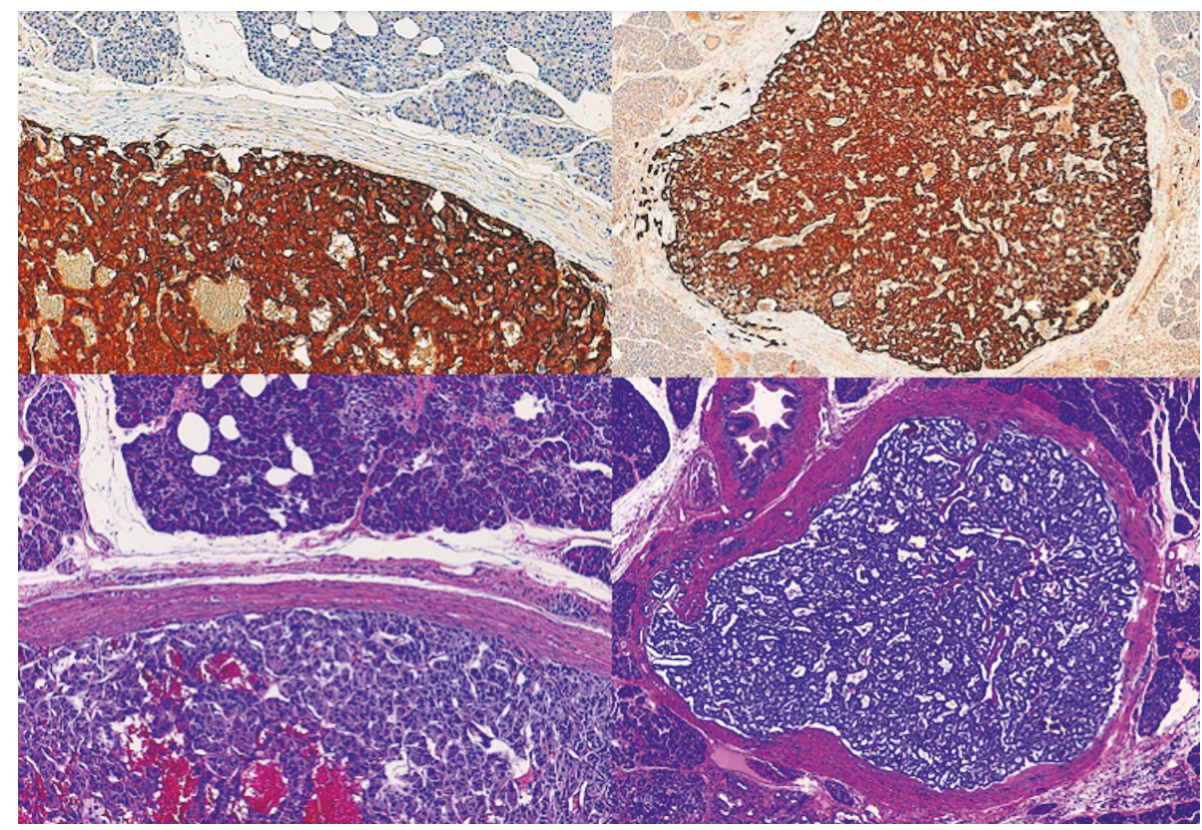

FIGURE 4: Immunohistochemistry with positive cells for glucagon.

Meningiomas represent $15-25 \%$ of all intracranial neoplasms, with an annual incidence of 6 per 100.000 people [8-11]. Radiotherapy is known to play a role in the appearance of intracranial tumors, but in cases such as ours, without prior exposition to radiotherapy, the origin is still unclear. Some authors suggest that it may happen by sheer chance, whereas others describe theories that may explain this association $[8,10]$. Suzuki et al. suggest an involvement of the activation of signaling pathways for the receptor tyrosine kinases [12], and Friend et al. showed that meningioma may express $\mathrm{GH}$ and IGF1 receptors [13]. Although there are cases described in the literature of an association of meningioma with functioning and nonfunctioning pituitary adenomas, in the case of functioning adenomas, $\mathrm{GH}$-producing varieties seem to predominate $[9,10,14]$. It remains to be seen whether $\mathrm{GH}$ itself or an overexpression of IGF1 receptors in these tumors induces a transformation into a meningioma. On the other hand, Asgharian et al. proved in a prospective study of 74 patients with MEN1 that $8 \%$ of the patients developed meningioma after 18 years of follow-up, and it is believed that the alterations in the MEN1 gene may have participated in its pathogenesis [15].

\section{Conflicts of Interest}

The authors declare that there are no conflicts of interest.

\section{Authors' Contributions}

Dr. Herrero-Ruiz collected data, analyzed all patient data, wrote the final paper, and intervened in the care of the patient; Dr. Villanueva-Alvarado collected data, analyzed all patient data, wrote the first draft, and intervened in the care of the patient; Dr. Corrales-Hernández, Dr. Higueruela-Mínguez, and Dr. Feito-Pérez intervened in the care of the patient; Dr. Recio-Cordova intervened in the care and follow-up of the patient.

\section{References}

[1] O. Alexopoulou, M. Bex, P. Kamenicky, A. B. Mvoula, P. Chanson, and D. Maiter, "Prevalence and risk factors of impaired glucose tolerance and diabetes mellitus at diagnosis of acromegaly: A study in 148 patients," The Pituitary Society, vol. 17, no. 1, pp. 81-89, 2014.

[2] E. Resmini, F. Minuto, A. Colao, and D. Ferone, "Secondary diabetes associated with principal endocrinopathies: the impact of new treatment modalities," Acta Diabetologica, vol. 46, no. 2, pp. 85-95, 2009.

[3] S. Fieffe, I. Morange, P. Petrossians et al., "Diabetes in acromegaly, prevalence, risk factors, and evolution: data from the French Acromegaly Registry," European Journal of Endocrinology, vol. 164, no. 6, pp. 877-884, 2011.

[4] M. Carrasco de la Fuente, O. González-Albarrán, G. Pérez López, and M. Cano Megías, "Diabetic ketoacidosis as the first manifestation of a mixed growth hormone and prolactinsecreting tumor," Endocrinología y Nutrición, vol. 57, no. 10, pp. 507-509, 2010.

[5] C. Galesanu, C. Buzduga, A. Florescu, and L. Moisii, "Diabetes mellitus, chronic complication in patients with acromegaly: case report and review of the literature," Rev Med Chir Soc Med Nat Iasi, vol. 119, no. 1, pp. 92-96, 2015.

[6] J. D. N. Nabarro, "Acromegaly," Clinical Endocrinology (Oxf), vol. 26, no. 4, pp. 481-512, 1987.

[7] R. W. McCallum, V. Parameswaran, and J. R. Burgess, "Multiple endocrine neoplasia type 1 (MEN 1) is associated with an increased prevalence of diabetes mellitus and impaired fasting glucose," Clinical Endocrinology, vol. 65, no. 2, pp. 163-168, 2006. 
[8] D. Moncet and G. B. Isaac, "Simultaneous association of pituitary adenoma and meningioma: report of three cases," Revista Argentina de Endocrinología y Metabolismo, vol. 52, pp. 29-34, 2015.

[9] F. Ruiz-Juretschke, B. Iza, E. Scola-Pliego, D. Poletti, and E. Salinero, "Coincidental pituitary adenoma and planum sphenoidale meningioma mimicking a single tumor," Endocrinología y Nutrición, vol. 62, no. 6, pp. 292-294, 2015.

[10] S. Mortazavi, A. Shirani M, S. Saeedinia, R. Sanjari, H. Hanif, and A. Amirjamshidi, "Coexisting pituitary adenoma and suprasellar meningioma: a coincidence or causation effect? report of two cases and review of literature," IrJNS, vol. 1, 43, no. 1, p. 46.

[11] L. Curto, S. Squadrito, B. Almoto et al., "MRI finding of simultaneous coexistence of growth hormone-secreting pituitary adenoma with intracranial meningioma and carotid artery aneurysms: report of a case," The Pituitary Society, vol. 10, no. 3, pp. 299-305, 2007.

[12] K. Suzuki, H. Momota, A. Tonooka et al., "Glioblastoma simultaneously present with adjacent meningioma: Case report and review of the literature," Journal of Neuro-Oncology, vol. 99, no. 1, pp. 147-153, 2010.

[13] K. E. Friend, R. Radinsky, and I. E. McCutcheon, "Growth hormone receptor expression and function in meningiomas: Effect of a specific receptor antagonist," Journal of Neurosurgery, vol. 91, no. 1, pp. 93-99, 1999.

[14] S. Cannavò, L. Curtò, R. Fazio et al., "Coexistence of growth hormone-secreting pituitary adenoma and intracranial meningioma: A case report and review of the literature," Journal of Endocrinological Investigation, vol. 16, no. 9, pp. 703-708, 1993.

[15] B. Asgharian, Y.-J. Chen, N. J. Patronas et al., "Meningiomas May Be a Component Tumor of Multiple Endocrine Neoplasia Type 1," Clinical Cancer Research, vol. 10, no. 3, pp. 869-880, 2004. 


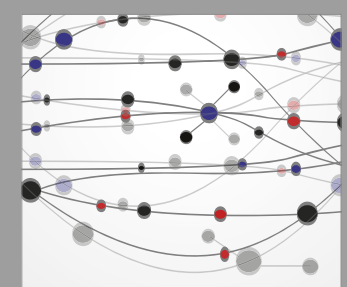

The Scientific World Journal
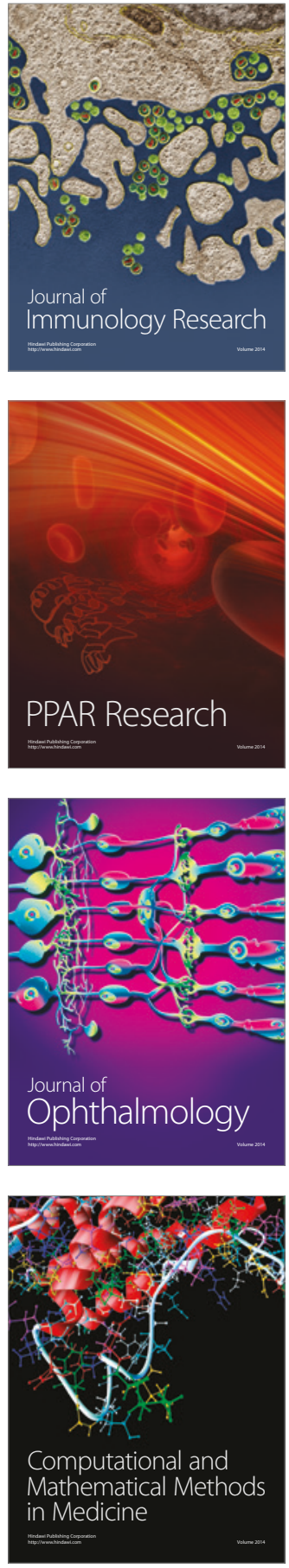

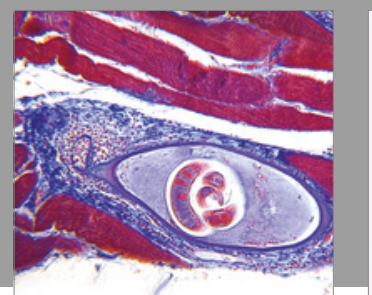

Gastroenterology Research and Practice
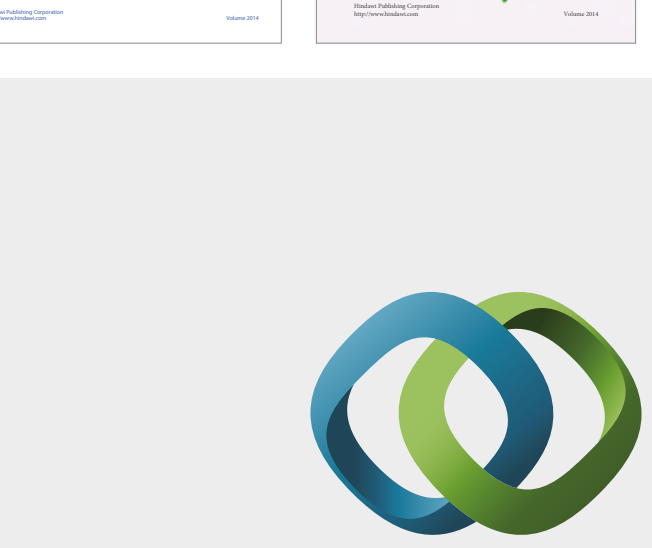

\section{Hindawi}

Submit your manuscripts at

https://www.hindawi.com
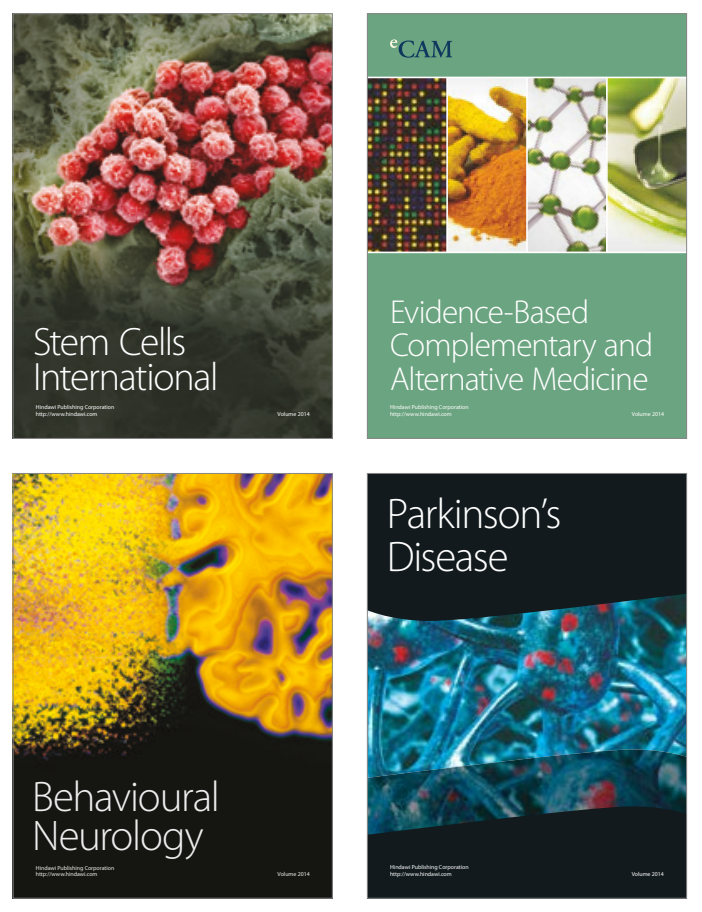
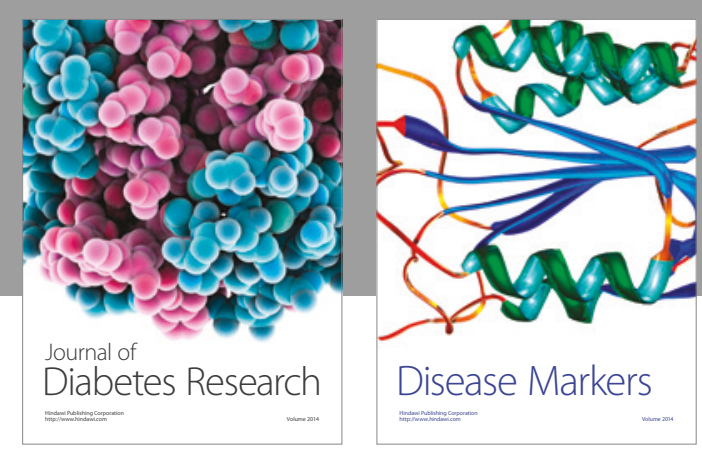

Disease Markers
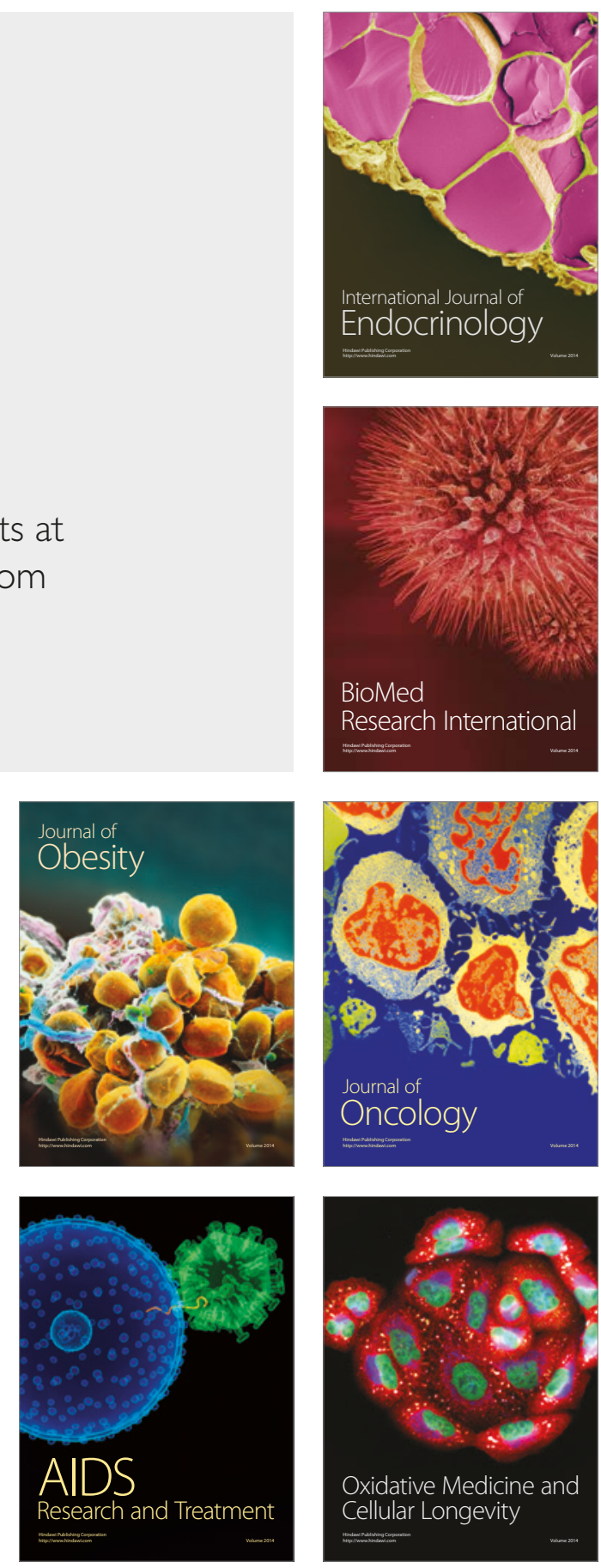